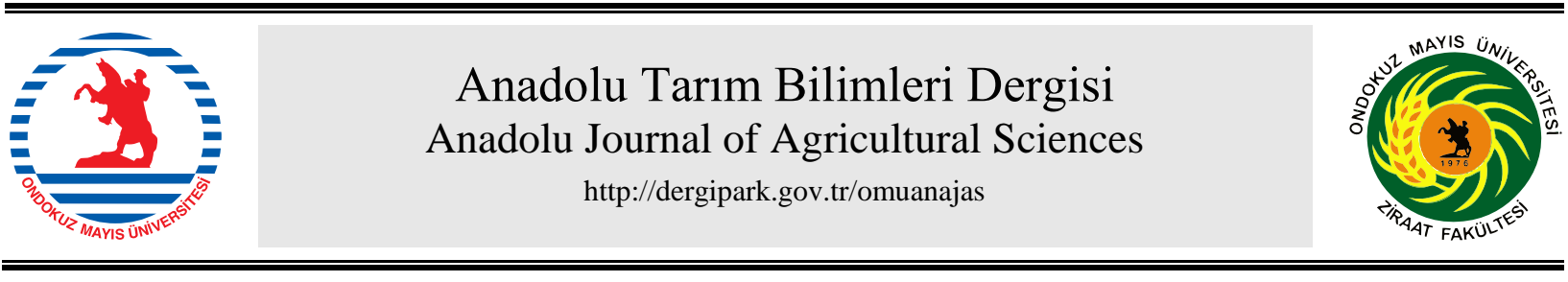

Araştırma/Research

Anadolu Tarım Bilim. Derg./Anadolu J Agr Sci, 32 (2017)

ISSN: 1308-8750 (Print) 1308-8769 (Online)

doi: 10.7161/omuanajas.297081

\title{
Kivilerde kök çürüklüğü hastalığına neden olan bazı funguslara karşı organik ve inorganik tuzların engelleyici etkilerinin belirlenmesi
}

\author{
Mehmet Yaman, Muharrem Türkkan* \\ Ordu Üniversitesi, Ziraat Fakültesi, Bitki Koruma Bölümü, 52200 Merkez, Ordu \\ "Sorumlu yazar/corresponding author: muharremturkkan@odu.edu.tr
}

Geliş/Received 09/03/2017 Kabul/Accepted 20/09/2017

\section{ÖZET}

Bu çalışmada kivilerde kök çürüklüğü etmeni Fusarium oxysporum, F. solani ve Rhizoctonia solani AG 4'e karş1 21 organik ve inorganik tuz ve sentetik fungisit olarak Captan'ın etkinliği değerlendirilmiştir. In vitro ön denemelere göre, amonyum karbonat, amonyum bikarbonat, potasyum benzoat, potasyum sorbat, sodyum benzoat, sodyum metabisülfit ve Captan'ın da dahil olduğu 7 bileşiğin $\% 2$ konsantrasyonda üç fungusun miselyal gelişimini tamamen engellediği belirlenmiştir. Bu çalışma, birkaç istisna dışında, sodyum metabisülfitin funguslara karşı diğer 6 bileşikten daha büyük bir etkiye sahip $\mathrm{ED}_{50}$, MIC ve MFC değerlerine sahip olduğunu göstermiştir. Toprak testleri amonyum karbonat (\% 0.75), amonyum bikarbonat (\% 1$)$, potasyum sorbat $(\% 0.5)$, sodyum benzoat $(\% 0.5)$ ve sodyum metabisülfit (\% 0.25)'in $R$. solani AG 4'ün miselyal gelişmesini tamamen engellediğini, buna karşın Captan'ın \% 95.23'e kadar azalttığını göstermiştir, ancak bunların engelleyici etkileri arasındaki farklılık istatistiksel olarak önemsiz $(\mathrm{P}<0.05)$ bulunmuştur. Ayrıca üç fungusa karș1 \% 0.25 sodyum metabisülfit, \% 0.25 Captan, \% 0.25 potasyum sorbat, \% 0.75 amonyum karbonat ve $\% 1$ amonyum bikarbonat uygulamalarının engelleyici etkileri arasında önemli bir fark tespit edilmemiştir $(\mathrm{P}<0.05)$. Kök testlerinde her üç fungusa karş1 \% 0.1 sodyum metabisülfit ve \% 0.25 Captan uygulamalarının kivi fidelerindeki kök çürüklüğü şiddetini patojenlerle inokuleli kontrol bitkilerine kıyasla önemli oranda azalttığ1, ancak \% 0.75 amonyum karbonat, \% 1 amonyum bikarbonat, \% 0.25 potasyum benzoat, \% 0.25 potasyum sorbat ve $\% 0.25$ sodyum benzoat uygulamalarının kök çürüklügü şiddetini azaltmadığı saptanmiştır $(\mathrm{P}<0.05)$.

Determination of the inhibitory effects of organic and inorganic salts against some fungi causing root rot disease on kiwifruit

\footnotetext{
ABSTRACT

The efficacy of 21 organic and inorganic salts and Captan as a senthetic fungicide against three kiwifruit root rot pathogens including Fusarium oxysporum, F. solani and Rhizoctonia solani AG 4 were evaluated in the present study. According to the preliminary in vitro trials, 7 compounds including ammonium carbonate, ammonium bicarbonate, potassium benzoate, potassium sorbate, sodium benzoate, sodium metabisulphite and Captan $(2 \%)$ were able to completely inhibit mycelial growth of all three fungi. With few exceptions, this study showed that sodium metabisulphite had the $\mathrm{ED}_{50}$, MIC and MFC values having a greater effect against the fungi than six other compounds. Soil tests showed that ammonium carbonate $(0.75 \%)$, ammonium bicarbonate $(1 \%)$, potassium sorbate $(0.5$ $\%)$, sodium benzoate $(0.5 \%)$ and sodium metabisulphite $(0.25 \%)$ completely inhibited mycelial growth of $R$. solani AG 4, whereas Captan reduced the mycelial growth of the fungus by $95.23 \%$; however, differences among the inhibitory effects of treatments were found to be statistically insignificant $(\mathrm{P}<0.05)$. In addition, there was no significant differences among the inhibitory effects of $0.25 \%$ sodium metabisulphite, $0.25 \%$ Captan, $0.25 \%$ potassium sorbate, $0.75 \%$ ammonium carbonate and 1 $\%$ ammonium bicarbonate against all three fungi $(\mathrm{P}<0.05)$. In the root tests, the treatments of $0.1 \%$ sodium metabisulphite and $0.25 \%$ Captan against each three fungi significantly reduced the severity of root rot in kiwifruit seedlings in comparison to the inoculated control plants, but $0.75 \%$ ammonium carbonate, $1 \%$ ammonium bicarbonate, $0.25 \%$ potassium benzoate, $0.25 \%$ potassium sorbate and 0.25 $\%$ sodium benzoate did not $(\mathrm{P}<0.05)$.
}

Anahtar Sözcükler: Alternatif mücadele Captan Fusarium oxysporum F. solani Rhizoctonia solani AG 4

Keywords:

Alternative control Captan

Fusarium oxysporum

F. solani

Rhizoctonia solani AG 4 


\section{Giriş}

Türkiye'de kivi [Actinidia deliciosa (A. Chev.) C. F. Liang \& A. R. Ferg.] üretimi, 2016 y1lı verilerine göre toplam 32.000 da alandan 41.635 ton olarak gerçekleşmiştir (FAO, 2016). Bu üretimde Ordu ili 6.263 ton ile Yalova (18.892)'dan sonra 2. sirada yer almaktadır. Karadeniz Bölgesi (Artvin, Bartın, Düzce, Giresun, Kastamonu, Ordu, Rize, Samsun, Sinop, Trabzon ve Zonguldak) kivi yetiştiriciliği yapılan alanların \% 57.2 (13.792 da)'sini kapsamakta olup, toplam üretimdeki payı \% 45.4 (18.912 ton)'tür (TÜIK, 2016). Bölgede 2000 yılında başlanan kivi yetiştiriciliğinde, son yıllarda tesis edilen kivi bahçelerinin sayısındaki artış ile beraber üretimde de önemli artışlar yaşanmaktadır. Ancak bu aynı zamanda kivi yetiştiricilerinin çeşitli bitki koruma problemleri ile yüz yüze gelmesine neden olmuştur. $\mathrm{Bu}$ şikayetlere yönelik olarak farklı araştırıcılar tarafından yapılan çalışmalar ile kivi yetiştiriciliği alanlarında sorun olan hastalık, zararlı ve yabancı otlar ile ilgili tespitler rapor edilmiştir (Karakaya, 2001; Erper ve ark., 2011a; Ak ve ark., 2011; Baştaş ve Karakaya, 2012; Güncan, 2015; Yonat, 2016).

Dünyanın farklı ekolojik koşullarında kivi üretimini olumsuz olarak etkileyen çok sayıda kök ve gövde çürüklüğü etmen [Armillaria spp. (A. novae-zelandiae, A. mellea), Botryosphaeria dothidea, Cylindrocladium crotalaria, Cadophora spp. (C. luteo-olivacea, C. malorum, C. melinii), Fomitiporia punctata, Fusarium spp. (F. stilboides ve $F$. coccophilum), Lecythophora luteoviridis, Phaeoacremonium spp. (P. aleophilum, $P$. iranianum, $P$. mortoniae, $P$. parasiticum, $P$. viticola), Phytophthora spp. (P. cactorum, P. cinnamomi, $P$. citricola, P. citrophthora, P. cryptogea, P. drechsleri, $P$. gonapodyides, $P$. lateralis, $P$. nicotiana, $P$. megasperma), Rhizoctonia solani, Rosellinia necatrix ve Verticillium dahliae]'leri tespit edilmiş olup (Brook, 1986; Krausz ve Caldwell, 1987; Conn ve ark., 1991; Latorre ve ark., 1991; Anonim, 1999; Elena ve Paplomatas, 2002; Di Marco ve ark., 2000, 2003, 2004; Prodi ve ark., 2008; Thomidis ve Exadaktylou, 2010), bu patojenlerin bir kısmı Türkiye'de Karadeniz Bölgesi'nde belirlenmiştir. Bu hastalık etmenlerinden özellikle fungal kök çürüklüğü etmenleri Cylindrocarpon pauciseptatum, Cylindrocladiella parva, Ilyonectria spp. (I. europaea, I. liriodendri, I. robusta ve $I$. torresensis) ve Phytophthora spp. ( $P$. citrophthora, $P$. cryptogea ve $P$. megasperma) rapor edilmiştir (Ak1llı ve ark., 2011; Erper ve ark., 2011a; Erper ve ark., 2013; Kurbetli ve Ozan, 2013). Ayrıca Ordu ili kivi yetiştiriciliği yapılan alanlardan da Cylindrocarpon sp., Fusarium sp., Macrophomina phaseolina, Pythium sp. ve Rhizoctonia sp. gibi kök çürüklüğü etmenleri tespit edilmiştir. $\mathrm{Bu}$ etmenler arasında özellikle $F$. oxysporum, $F$. solani ve Rhizoctonia solani AG 4 türlerinin diğerlerinden daha sık izole edildiği ve yapılan patojenisite testlerinde $F$. solani'nin diğer iki etmenden daha şiddetli kök çürüklüğüne neden olduğu bildirilmiştir (Türkkan, 2017).

Toprak kökenli fungal hastalık etmenleri ile mücadelede sağlıklı üretim materyali kullanılması, topraktaki fazla suyun drenaj edilmesi, enfekteli bitki artıklarının alandan uzaklaştırılması, dengeli gübreleme ve sulama gibi kültürel önlemler, bitkisel materyallerin sicak suya daldırılması ve toprak solarizasyonu gibi fiziksel önlemler, dayanıklı bitki çeşitlerinin yetiştirilmesi, topraktaki faydalı mikroorganizma (bakteri, fungus vd.)'ları harekete geçirmek için toprağa organik materyal (buğdaygil saplarının, lahanagillerin ve kitosan eklenmesi)'ler ile zenginleştirilmesi ve arbuskular mikorhizal uygulamaları gibi biyolojik önlemlerin yanı sıra bitkisel materyalin çeşitli fungisitler (bakır oksiklorür, bakır sülfat, benomyl, captan, carbendazim, didecyldimethylammonium chloride, fosetyl-Al, hydroxyquinoline sulfat, imazalil, metalaxyl, prochloraz ve thiram) ile muamelesi ve toprak fumigasyonu (metam sodyum ve metil bromid) gibi kimyasal savaşım yöntemleri tavsiye edilmektedir (Farih ve ark., 1981; Yuen ve ark., 1991; Agrios, 2005; Alaniz ve ark., 2011). Ancak bu hastalık etmenleri ile mücadele, toprakta uzun yıllar canlılıklarını koruyabildikleri dayanıklı yapılarının olması (klamidospor, oospor, sklerot vb.), hepsine karşı etkili fungisitlerin olmaması, fungisitlere karşı direnç kazanmaları ve kullanılan fungisitlerin maliyetlerinin yüksek olması nedeniyle oldukça zordur (Yangui ve ark., 2008). Bu fungisit uygulamaları yetiştiriciliği yapılan ürünlerde ve toprakta kimyasal fungisit kalıntılarına neden olmakta, çevre ve insan sağlığını olumsuz bir şekilde etkilemektedir. Ayrıca bu etmenlere karşı mücadelede en etkili olan bazı fungisitler (benomyl, metil bromid) günümüzde hem dünyadaki gelişmiş ülkelerde hem de ülkemizde yasaklıdır (Fan ve ark., 2008). Kaldı ki ülkemizde kivilerde tespit edilen kök çürüklüğü etmenlerine karşı kullanılabilecek ruhsatlı bir fungisit bulunmamaktadır. Bu yüzden, bitki hastalıkları ile mücadelede yeni stratejiler içerisinde bitkinin gelişme sezonu içerisinde kullanılabilen az veya hiç sentetik fungisit içermeyen bileşiklerle patojenlerin mücadelesinin yapılmasına ihtiyaç duyulmaktadır. Günümüzde bu amaca ulaşmanın en iyi yollarından biri, çevre ve insan sağlığı üzerine olumsuz bir etkisi olmayan, genel olarak güvenli kabul edilen maddeler olan organik ve inorganik tuzların kullanımıdır (FDA, 2016). Bu tuzlar geniş bir antifungal aktiviteye sahip olup, önemli bir kısmı gida sanayinde koruyucu, $\mathrm{pH}$ düzenleyici, tat ve yap1 düzenleyici madde olarak kullanılmaktadır (Miyasaki ve ark., 1986; Corral ve ark., 1988; Olivier ve ark., 1998). Son yillarda amonyum, sodyum ve potasyumun organik ve inorganik tuzları bahçe ve tarla bitkilerinde, hasat sonu fungal bitki hastalıklarında, fidanlıklarda kök ve kök boğazı hastalıklarının yanı sıra çok sayıda toprak kökenli fungal hastalık etmenine karşı kullanılmış ve başarılı 
sonuçlar alınmıştır (DePasquale ve ark., 1990; Ziv ve Zitter, 1992; Punja ve Gaye, 1993; Palmer ve ark., 1997; Olivier ve ark., 1999; Campanella ve ark., 2002; Hervieux ve ark., 2002; Mecteau ve ark., 2002; Palou ve ark., 2002; Arslan ve ark., 2006; Reuveni ve ark., 1996; Valencia-Chamorro ve ark., 2008; Arslan ve ark., 2009; Latifa ve ark., 2011; Erper ve ark., 2011b; Arslan ve ark., 2013; Türkkan, 2013; Türkan ve Erper, 2014; Türkkan, 2015).

$\mathrm{Bu}$ çalışmada Ordu ili kivi bahçelerinde kök çürüklüğüne neden olan bazı fungal kök çürüklüğü etmenleri ( $F$. oxysporum, $F$. solani ve $R$. solani AG 4)'ne karş1 sentetik fungisitlere alternatif olarak kullanılabilecek bazı organik ve inorganik tuzların etkinliğinin belirlenmesi amaçlanmıştır.

\section{Materyal ve Yöntem}

\subsection{Materyal}

\section{1. 1. Fungal Kültür}

Çalışmada kullanılan Fusarium oxysporum, $F$. solani ve Rhizoctonia solani AG 4 kültürlerine ait izolatlar Ordu Üniversitesi Ziraat Fakültesi Bitki Koruma Bölümü Fitopatoloji Anabilim Dalı Mikoloji laboratuarındaki fungal kültür koleksiyonundan temin edilmiştir.

\section{1. 2. Organik Tuzlar ve Captan}

Çalışmada kullanılan 21 organik ve inorganik tuz Merck (Darmstadt, Almanya) ve Sigma-Aldrich (Seelze, Almanya)' den, Captan (Captan'H \% 50 WP, Hektaş, Kocaeli, Türkiye)'dan satın alınmıştır.

\subsection{Yöntem}

\section{2. 1. Organik ve İnorganik Tuzlar ve Captan'in Fungusların Miselyal Gelişmeleri Üzerine Etkilerinin ve Toksisitelerinin Belirlenmesi}

Organik ve inorganik tuzlar ve Captan'ın \%2'lik konsantrasyonları otoklav (Nüve OT 40L SteamArt, Akyurt, Ankara, Türkiye)'da $121^{\circ} \mathrm{C}$ 'de 20 dakika sterilize edilmiş ve $50^{\circ} \mathrm{C}$ 'de soğutulmuş $100 \mathrm{ml}$ 'lik erlenlerdeki patates dekstroz agar (PDA, BD Difco, Sparks, Amerika Birleşik Devletleri) besi ortamına eklenmiştir. Bileşiklerin manyetik karıştırıcı (MTOPS MS300HS, Misung Scietific Co., Ltd., Kore) ile karıştırılarak homojen bir şekilde tüm besi ortamına dağılması sağlandıktan sonra pH metre (Hanna HI 2211, Hanna Instruments, Almanya) ile pH'ları belirlenmiştir. Bileşiklerin \% 2 konsantrasyonlarını içeren PDA besi ortamları, 7 veya $9 \mathrm{~cm}$ çapındaki petri kaplarına 10-12 $\mathrm{ml}$ olacak şekilde paylaştırılmıştır. Bu petriler, daha önceden PDA besi ortamında geliştirilmiş 7-10 günlük fungus kültürlerinden mantar delici ile alınan $5 \mathrm{~mm}$ çaplı miselyal disklerle inokule edilmiştir. Petriler parafilm ile kaplandıktan sonra $24 \pm 1^{\circ} \mathrm{C}$ 'de inkübe edilmiştir. Aynı koşullarda inkübe edilen kontrol grubu (sadece PDA besi ortamı içeren) petrilerdeki fungusların gelişmeleri günlük olarak izlenerek petriyi kaplamaya yakın olduğunda, kontrol ve farklı bileşikleri içeren petrilerdeki fungusların gelişmeleri dijital kumpas (TorQ 150 mm Digital Caliper, Çin Halk Cumhuriyeti) ile ölçülerek belirlenmiştir. Ölçümler sırasında fungusların en uzun ve kısa radyal gelişmeleri esas alınmıştır. Deneme her bileşik için 6 tekerrürlü olarak yürütülmüştür. Miselyal gelişmenin engellenmesi aşağıdaki formül kullanılarak hesaplanmıştır (Mecteau ve ark., 2002).

$$
\begin{aligned}
& \text { MGE }(\%)=[(\mathrm{kpfg}-\text { bepfg }) / \mathrm{kpfg}] \times 100 \\
& \operatorname{MGE}(\%)=\text { miselyal gelişmenin yüzde olarak } \\
& \text { engellemesi } \\
& \mathrm{kpfg}=\text { kontrol petrilerindeki fungal gelişme } \\
& \text { bepfg }=\text { bileşik eklenmiş petrilerdeki fungal gelişme }
\end{aligned}
$$

Fungusların miselyal gelişmesini \% 50 oranında engelleyen bileşiklerin konsantrasyonlarını $\left(\mathrm{ED}_{50}=\right.$ etkili doz) belirlemek için bunların farklı konsantrasyonları $(\% 0.025,0.05,0.1,0.25,0.5,1.0$ ve 2.0)'nı içeren petri kapları yukarıda belirtildiği şekilde hazırlanmıştır. Buradan elde edilen sonuçlar IBM SPSS Statistic paket programı kullanılarak probit analizi ile $\mathrm{ED}_{50}$ değerleri hesaplanmıştır. Miselyal gelişmeyi tamamen engelleyen en küçük konsantrasyon (MIC = minimum inhibition concentration) ise paralel denemelerle gözlemsel olarak besin ortamında gelişmeyen en küçük konsantrasyon esas alınarak tespit edilmiştir.

Bileşiklerin fungisidal veya fungistatik etkileri Thompson, (1989) ve Tripathi ve ark., (2004)'nın metodları izlenerek belirlenmiştir. Ayrıca gelişmeyen fungus diskleri petrilerden alınarak, taze besin ortamı içeren petrilere aktarılmış ve gelişmeleri $24 \pm 1^{\circ} \mathrm{C}$ 'de 9 gün boyunca izlenmiştir. Bu sürede fungusta geri dönüşümsüz olarak hiç bir miselyal gelişme belirlenmemişse, bu konsantrasyon fungusun miselyal gelişimine fungisidal etki yapan minimum konsantrasyon $(\mathrm{MFC}=$ minimum fungicidal concentration) olarak belirlenmiştir.

\section{2. 2. Toprak Testi}

Bu testte, in vitro'da $F$. oxysporum, $F$. solani ve $R$. solani AG 4'ün misel gelişimini tamamen engelleyen organik ve inorganik tuzlar ile Captan kullanılmıştır. Arslan ve ark., (2009)'na göre hazırlanan misır unukum karışımı $7 \mathrm{~cm}$ çapındaki cam petrilere konulup, $130^{\circ} \mathrm{C}$ 'de 5 saat süre ile etüvde (Ecocell LSISB2V/EC111; MMM Group, Planegg, Almanya) steril edilmiştir. PDA ortamında 7-10 gün geliştirilmiş fungal kültürlerden mantar delici $(5 \mathrm{~mm})$ ile alınan diskler 0.5 $\mathrm{cm}$ derinlikteki mısır unu-kum karışımı ortamına konulmuştur. Amonyum karbonat ve bikarbonat için \% 0.75 ve 1 ; potasyum benzoat, potasyum sorbat, sodyum 
benzoat ve Captan için \% 0.25 ve 0.5 ; sodyum metabisülfit için \% 0.1 ve 0.25 'lik konsantrasyonlar, steril saf su kullanılarak hazırlanmış ve bunların solüsyonlarının $12 \mathrm{ml}$ 'si petrilere cam pipet kullanılarak eklenmiştir. Petriler $25^{\circ} \mathrm{C}$ 'de $4-8$ gün süre boyunca karanlıkta inkübe edilmiştir. $\mathrm{Bu}$ süre sonunda petrilerdeki fungal gelişme petri kapağı üzerine yerleştirilen asetat kağıdına fungal gelişmenin sınırları çizilerek aktarılmıştır. Asetat kağıtlarındaki çizimler üzerinde 5 cm'lik bar olan beyaz A4 kağıtlarına aktarılmış ve Mustek 1200 UB Plus (Mustek Systems, Inc., Hsin Chu, Taiwan, Çin Halk Cumhuriyeti), masaüstü tarayıc1 ile taranarak 24-bit bmp dosyası olarak kaydedilmiştir. Daha sonra Digimizer programı (Version 4.0.0.0 for Windows 2005-2011 MedCalc Software bvba Broekstraat 52, 9030 Mariakerke, Belçika) kullanılarak bunların yüzey alanları hesaplanmıştır. Fungusların miselyal gelişmesi ile kontroldeki miselyal gelişmenin karşılaştırılması sonucunda elde edilen veriler yüzde engelleme değerlerine dönüştürülerek bileşiklerin engelleme yüzdeleri belirlenmiştir. Deneme 5 tekerrürlü olarak yürütülmüştür.

\section{2. 3. Kök Testi}

Bu test Türkkan (2015)'in metodu kısmen modifiye edilerek yapılmıştır. $\mathrm{Bu}$ metoda göre 2-4 yapraklı Hayward cinsi kivi fidanları steril \% 70 toprak ve \% 30 kum karışımı içeren 0.81 saksılarda yetiştirilmiştir. Fungus kültürleri ile inokule edilmiş misır unu-kum karışımları cam şişeler içerisinde 3 hafta süreyle $25^{\circ} \mathrm{C}$ 'de inkübe edilmiştir. Gelişen fungal kültürlerden hazırlanan inokulum (w/w, \% 5) ile kivi fidanlarının kök bölgeleri inokule edilmiştir. Yukarıdaki toprak testinde funguslara karşı etkili bulunan ve kivi fidanlarında fitotoksisiteye neden olmayan bileşik konsantrasyonları steril saf su içerisinde çözülerek solüsyonları hazırlanmış ve bu solüsyonlardan her bir saksıya $100 \mathrm{ml}$ ilave edilmiștir. Saksılar $25 \pm 2^{\circ} \mathrm{C}$ 'deki bitki yetiştirme odasına yerleştirilmiş ve 6 gün boyunca sulanmamıştır. Altıncı günün sonunda bitkilere her 3-4 günde bir su verilmiş ve kivi fidanları 48 gün sonra sökülüp $\quad 0-5$ kök çürüklüğü skalasına göre değerlendirilmiştir (Erper ve ark., 2013). Kök uzunlukları ve yaş ağırlıkları belirlenmiş ve daha sonra kökler $60^{\circ} \mathrm{C}$ 'de kurutulup kök kuru ağırlıkları da belirlenmiştir. Deneme 3 tekerrürlü olarak yürütülmüştür.

\section{2. 4. Istatistik Analiz}

Tüm istatatistik analizler IBM SPSS istatistik program (version 19, Property of SPSS, Inc., IBM Company, USA)'1 kullanılarak yapılmıştır. Sonuçlar ayrı ayrı tek yönlü varyans analizine tabi tutularak, ortalamalar arasındaki önemli farklılıklar Tukey-HSD
$(\mathrm{P}<0.05)$ testine göre belirlenmiştir.

\section{Bulgular ve Tartışma}

Çalışmada kullanılan 21 organik ve inorganik tuz ile Captan'1n \% 2 konsantrasyonlarında $F$. oxysporum, $F$. solani, $R$. solani AG 4'e karş1 engelleyici etkilerinin birbirinden farklı olduğu belirlenmiştir (Çizelge 1). Bu bileşikler arasında amonyum bikarbonat, amonyum karbonat, potasyum sorbat, sodyum benzoat, sodyum metabisülfit ve Captan, $F$. oxysporum, $F$. solani ve $R$. solani AG 4'ün miselyal gelişmesini tamamen engellemiş ve bu sonuç her üç fungus için de istatiksel olarak diğer organik ve inorganik tuzlardan farklı bulunmuştur $(\mathrm{P}<0.05)$. Potasyum karbonat, sodyum bikarbonat ve sodyum karbonat $R$. solani AG 4'ün miselyal gelişmesini tamamen engellemesine karşın, potasyum benzoat \% 68.13 oranında bir engelleme sağlamıştır. Ancak potasyum benzoat hem $F$. oxysporum hem de $F$. solani' yi tamamen engellemiş, fakat diğerlerinin \% 43.53-89.45 arasında bir engelleme gösterdiği belirlenmiştir. Kalsiyum propionat $R$. solani AG 4'ün miselyal gelişmesini $\% 95.86$ oranında engellemesine rağmen, yukarıda tam engelleme gerçekleştiren 9 organik ve inorganik bileşikten istatiksel olarak farksız bulunmuştur $(\mathrm{P}<0.05)$. Ayrıca kalsiyum asetat, $F$. oxysporum ve $R$. solani AG 4'ün miselyal gelişmesini kontrole kıyasla sırasıyla \% 14.39 ve 66.62 oranında engellemesine karşın, $F$. solani'nin miselyal gelişmesini artırmış, fakat bu istatistiksel olarak kontrolden farklı bulunmamıştır $(\mathrm{P}<0.05)$.

Birkaç istisna dışında (kalsiyum sitrat ve sodyum tartarat) diğer tuzların $R$. solani'nin miselyal gelişmesini daha etkili bir şekilde engellediği görülmüştür. Ayrıca $\% 2$ konsantrasyonda organik ve inorganik tuzlar ile Captan'in pH değerlerinin 4.80-10.65 arasında değiştiği belirlenmiştir.

Yirmi bir organik ve inorganik tuz ile Captan'ın $\mathrm{ED}_{50}$, MIC ve MFC değerlerinin $F$. oxysporum, $F$. solani ve $R$. solani AG 4 için birbirinden farklı olduğu tespit edilmiştir (Çizelge 2). Bunlardan amonyum bikarbonat, amonyum karbonat, potasyum benzoat, potasyum sorbat, sodyum benzoat, sodyum metabisülfit ve Captan'ın her üç fungus için de yüksek fungitoksik etkiye sahip bileşikler olduğu, fakat diğerlerinin toksik etkilerinin düşük olmakla birlikte $R$. solani AG 4'e karş1 Fusarium türlerinden daha etkili oldukları belirlenmiş̧ir.

Amonyum karbonat ve bikarbonat tuzlarının diğer karbonat ve bikarbonatlardan daha yüksek bir fungitoksik etkinlik gösterdiği, MIC değerlerinin $F$. oxysporum ve $F$. solani için \% 0.5 iken $R$. solani AG 4 için ise \% 0.25 olduğu belirlenmiştir. Ayrıca birkaç istisna dışında, sodyum metabisülfitin bu üç fungusa karş1 en düşük $\mathrm{ED}_{50}$, MIC ve MFC değerlerine sahip olduğu tespit edilmiştir. 
Çizelge 1. Organik ve inorganik tuzlar ile Captan'ın \% 2'lik konsantrasyonlarının Fusarium oxysporum, Fusarium solani ve Rhizoctonia solani AG 4'ün miselyal gelişmesi üzerine etkileri ve $\mathrm{pH}$ değerleri

\begin{tabular}{|c|c|c|c|c|}
\hline \multirow{2}{*}{ Bileşikler } & \multirow{2}{*}{ pH } & \multicolumn{3}{|c|}{$\%$ Engelleme } \\
\hline & & F. oxysporum & F. solani & R. solani AG 4 \\
\hline A. asetat* & 6.50 & $28.36 \mathrm{fg}^{\mathrm{a}}$ & $21.31 \mathrm{fg}$ & $73.56 \mathrm{c}$ \\
\hline A. bikarbonat & 8.06 & $100.00 \mathrm{a}$ & $100.00 \mathrm{a}$ & $100.00 \mathrm{a}$ \\
\hline A. karbonat & 8.64 & $100.00 \mathrm{a}$ & $100.00 \mathrm{a}$ & $100.00 \mathrm{a}$ \\
\hline K. asetat & 4.80 & $14.39 \mathrm{i}$ & $-2.33 j$ & $66.62 \mathrm{e}$ \\
\hline K. propiyonat & 9.10 & $42.81 \mathrm{e}$ & $30.50 \mathrm{de}$ & $95.86 \mathrm{ab}$ \\
\hline K. silikat & 5.15 & $53.32 \mathrm{~d}$ & $35.69 \mathrm{~d}$ & $41.20 \mathrm{~g}$ \\
\hline K. sitrat & 6.70 & $15.86 \mathrm{i}$ & 26.50 ef & $0.74 \mathrm{ij}$ \\
\hline P. benzoat & 6.18 & $100.00 \mathrm{a}$ & $100.00 \mathrm{a}$ & $68.13 \mathrm{de}$ \\
\hline P. bikarbonat & 8.40 & 26.07 f-h & $35.67 \mathrm{~d}$ & $71.44 \mathrm{~cd}$ \\
\hline P. karbonat & 10.60 & $43.53 \mathrm{e}$ & $52.36 \mathrm{c}$ & $100.00 \mathrm{a}$ \\
\hline P. sorbat & 6.51 & $100.00 \mathrm{a}$ & $100.00 \mathrm{a}$ & $100.00 \mathrm{a}$ \\
\hline S. asetat & 6.71 & $32.61 \mathrm{f}$ & $10.63 \mathrm{i}$ & $50.92 \mathrm{f}$ \\
\hline S. benzoat & 6.27 & $100.00 \mathrm{a}$ & $100.00 \mathrm{a}$ & $100.00 \mathrm{a}$ \\
\hline S. bikarbonat & 8.26 & $64.67 \mathrm{c}$ & $46.67 \mathrm{c}$ & $100.00 \mathrm{a}$ \\
\hline S. format & 6.00 & $21.92 \mathrm{~g}-\mathrm{i}$ & $11.24 \mathrm{i}$ & 69.48 c-e \\
\hline S. karbonat & 10.65 & $89.45 \mathrm{~b}$ & $88.19 \mathrm{~b}$ & $100.00 \mathrm{a}$ \\
\hline S. metabisülfit & 4.84 & $100.00 \mathrm{a}$ & $100.00 \mathrm{a}$ & $100.00 \mathrm{a}$ \\
\hline S. propiyonat & 6.81 & $52.14 \mathrm{~d}$ & $50.51 \mathrm{c}$ & $94.48 \quad \mathrm{~b}$ \\
\hline S. sitrat & 7.08 & $60.02 \mathrm{~cd}$ & $33.17 \mathrm{de}$ & $92.84 \mathrm{~b}$ \\
\hline S. süksinat & 7.05 & $18.50 \mathrm{hi}$ & $12.54 \mathrm{i}$ & $16.40 \mathrm{hi}$ \\
\hline S. tartarat & 6.10 & 18.38 hi & 13.79 hi & $4.78 \mathrm{i}$ \\
\hline Captan & 5.11 & $100.00 \mathrm{a}$ & $100.00 \mathrm{a}$ & $100.00 \mathrm{a}$ \\
\hline Kontrol & 5.78 & $0.00 \mathrm{j}$ & $0.00 \mathrm{j}$ & $0.00 \mathrm{j}$ \\
\hline
\end{tabular}

$\mathrm{A}=$ Amonyum, $\mathrm{K}=$ Kalsiyum, $\mathrm{P}=$ Potasyum ve $\mathrm{S}=$ Sodyum kısaltmaların ifade etmektedir.

aAynı sütünda yer alan ve aynı harfle gösterilen değerler için Tukey-HSD P $<0.05$ 'e göre fark yoktur.

Organik ve inorganik tuzlardan bazıları ve Captan'ın fungitoksik etkileri Çizelge 3'te belirtilmiştir. Amonyum karbonat ve bikarbonatın fungistatik etkilerinin $F$. oxysporum, $F$. solani ve $R$. solani $\mathrm{AG} 4$ için benzer olduğu, fakat her iki tuzun $R$. solani AG 4'e karş1 daha yüksek bir fungitoksik etki gösterdiği belirlenmiştir. Ayrıca diğer karbonat ve bikarbonat tuzlarının aksine amonyum karbonat ve bikarbonat her üç fungusa karşı da fungisidal etki göstermiştir. Potasyum benzoat $R$. solani AG 4'e karşı herhangi bir fungitoksik etki göstermezken, sodyum benzoat \% $0.5^{\prime}$ 'te fungisidal etki göstermiştir. Potasyum sorbat $R$. solani AG 4'e karş1 \% 0.25 'te fungisidal etki göstermesine karşın, Fusarium türlerine karşı fungistatik etki göstermiştir. Captan her üç fungusa karşı fungisidal etki göstermiştir. Benzer olarak sodyum metabisülfitte $F$. oxysporum, $F$. solani ve $R$. solani AG 4'e karşı fungisidal etki göstermiş ve çalışmadaki en toksik bileşik olduğu belirlenmiştir. Toprak testinde potasyum benzoat ( $\% 0.25$ ve 0.5 )'in aksine, amonyum bikarbonat (\% 1), amonyum karbonat (\% 0.75 ve 1$)$, potasyum sorbat $(\% 0.25)$, sodyum metabisülfit $(\% 0.1$ ve 0.25 ) ve Captan (\% 0.25 ve 0.5 ) $F$. oxysporum, $F$. solani ve $R$. solani AG 4'ün miselyal gelişmesini ya yüksek bir oranda engellemiş ya da tamamen durdurmuştur ki, bu sonuç istatistiki olarak farklı bulunmuştur $(\mathrm{P}<0.05)$ (Çizelge 4). Ayrıca sodyum benzoatın \% 0.5 konsantrasyondaki engelleme değerleri $F$. oxysporum hariç, diğer iki fungus için yukarıdakilerden farksız bulunmuştur $(\mathrm{P}<0.05)$.

Kök testinde kivilerde kök çürüklüğüne neden olan $F$. oxysporum, $F$. solani ve $R$. solani AG 4'e karş1 kullanılan 7 organik ve inorganik tuz ve Captan'ın farklı konsantrasyonlarının etkinlikleri değerlendirilmiştir. Uygulamaların inokulum bulaştırılmış ve/veya inokulum bulaştırılmamış kontrol bitkilerine kıyasla kök çürüklüğü ve kök uzunluğu değerleri istatistiki olarak önemli iken $(\mathrm{P}<0.05)$, kök yaş ve kuru ağırlığı önemsiz bulunmuştur $(\mathrm{P}>0.05)$ (Çizelge 5). Sodyum metabisülfit ve Captan uygulamalarının her üç etmenin neden olduğu kök çürüklüğü şiddetini inokuleli kontrol bitkilerine kıyasla önemli oranda azalttığı belirlenmiştir 
Çizelge 2. Fusarium oxysporum, Fusarium solani ve Rhizoctonia solani AG 4'e karşı organik ve inorganik tuzlar ile Captan'ın $\mathrm{ED}_{50}$, MIC ve MFC değerleri $(\%, w / v)$

\begin{tabular}{|c|c|c|c|c|c|c|c|c|c|}
\hline \multirow{2}{*}{ Bileşikler } & \multicolumn{3}{|c|}{ F. oxysporum } & \multicolumn{3}{|c|}{ F. solani } & \multicolumn{3}{|c|}{ R. solani AG 4} \\
\hline & $* \mathbf{E D}_{50}$ & MIC & MFC & $\mathbf{E D}_{50}$ & MIC & MFC & $\mathbf{E D}_{50}$ & MIC & MFC \\
\hline A. asetat & $>2$ & $>2$ & $>2$ & $>2$ & $>2$ & $>2$ & 0.80 & $>2$ & $>2$ \\
\hline A. bikarbonat & 0.26 & 0.5 & 1 & 0.29 & 0.5 & 1 & 0.12 & 0.25 & 0.25 \\
\hline A. karbonat & 0.18 & 0.5 & 1 & 0.23 & 0.5 & 1 & 0.09 & 0.25 & 0.25 \\
\hline K. asetat & $>2$ & $>2$ & $>2$ & $>2$ & $>2$ & $>2$ & 0.68 & $>2$ & $>2$ \\
\hline K. propiyonat & $>2$ & $>2$ & $>2$ & $>2$ & $>2$ & $>2$ & 0.05 & $>2$ & $>2$ \\
\hline K. silikat & 0.96 & $>2$ & $>2$ & $>2$ & $>2$ & $>2$ & $>2$ & $>2$ & $>2$ \\
\hline K. sitrat & $>2$ & $>2$ & $>2$ & $>2$ & $>2$ & $>2$ & $>2$ & $>2$ & $>2$ \\
\hline P. benzoat & 0.30 & 1 & $>2$ & 0.22 & 1 & $>2$ & 0.53 & $>2$ & $>2$ \\
\hline P. bikarbonat & $>2$ & $>2$ & $>2$ & $>2$ & $>2$ & $>2$ & 1.69 & $>2$ & $>2$ \\
\hline P. karbonat & $>2$ & $>2$ & $>2$ & 1.53 & $>2$ & $>2$ & 0.29 & 1 & $>2$ \\
\hline P. sorbat & 0.05 & 0.25 & $>2$ & 0.04 & 0.1 & $>2$ & 0.06 & 0.25 & 0.25 \\
\hline S. asetat & $>2$ & $>2$ & $>2$ & $>2$ & $>2$ & $>2$ & $>2$ & $>2$ & $>2$ \\
\hline S. benzoat & 0.19 & 0.5 & $>2$ & 0.30 & 0.5 & 2 & 0.13 & 0.5 & 0.5 \\
\hline S. bikarbonat & 0.96 & $>2$ & $>2$ & $>2$ & $>2$ & $>2$ & 0.22 & 2 & $>2$ \\
\hline S. format & $>2$ & $>2$ & $>2$ & $>2$ & $>2$ & $>2$ & 0.69 & $>2$ & $>2$ \\
\hline S. karbonat & 0.42 & $>2$ & $>2$ & 1.02 & $>2$ & $>2$ & 0.27 & 1 & $>2$ \\
\hline S. metabisülfit & 0.07 & 0.25 & 0.25 & 0.05 & 0.25 & 0.25 & 0.03 & 0.1 & 0.1 \\
\hline S. propiyonat & $>2$ & $>2$ & $>2$ & $>2$ & $>2$ & $>2$ & 0.10 & $>2$ & $>2$ \\
\hline S. sitrat & 1.25 & $>2$ & $>2$ & $>2$ & $>2$ & $>2$ & 0.87 & $>2$ & $>2$ \\
\hline S. süksinat & $>2$ & $>2$ & $>2$ & $>2$ & $>2$ & $>2$ & $>2$ & $>2$ & $>2$ \\
\hline S. tartarat & $>2$ & $>2$ & $>2$ & $>2$ & $>2$ & $>2$ & $>2$ & $>2$ & $>2$ \\
\hline Captan & $<0.025$ & 2 & 2 & 0.03 & 1 & 1 & $<0.025$ & 1 & 2 \\
\hline
\end{tabular}

$* \mathrm{ED}_{50}=$ Effective dose, MIC=Minimum inhibition concentration, MFC=Minimum fungicidal concentration.

$(\mathrm{P}<0.05)$. Potasyum benzoat ve sorbat $F$. oxysporum ve $F$. solani'nin neden olduğu kök çürüklüğünü inokuleli kontrole kıyasla azaltırken, sodyum benzoat $R$. solani AG 4'ününkini azaltmış, ancak diğer funguslarınkini azaltamamıştır $(\mathrm{P}<0.05)$.

Amonyum bikarbonat $F$. oxysporum ve $R$. solani AG 4'ün neden olduğu kök çürüklüğü şiddetini azaltırken, amonyum karbonat sadece $F$. solani'ninkini azaltabilmiştir $(\mathrm{P}<0.05)$. Fidanların kök uzunluğu üzerine tüm uygulamaların hastalık etmenlerine karş1 etkili olduğu ve inokuleli kontrol bitkilerinden uygulama yapılan bitkilerin istatistiki olarak farklı olduğu belirlenmiştir $(\mathrm{P}<0.05)$. Ayrıca bu uygulamalardan bazıları ( $F$. oxysporum ve R. solani AG 4'e karş1 amonyum bikarbonat ve $R$. solani AG 4'e karş1 sodyum metabisülfit) inokule edilmemiş kontrol bitkilerinden istatistiki olarak farksız bulunmuştur $(\mathrm{P}<0.05)$.

Birçok çalışmada çeşitli bitki hastalıklarının mücadelesinde sentetik fungisitlere alternatif olarak kullanılabilecek farklı organik ve inorganik tuzların etkinliği in vitro, in vivo, sera ve tarla denemeleri ile değerlendirilmiş ve bu tuzlardan bikarbonat, fosfat, karbonat, klor, silikat, sülfit ve organik asit tuzlarının bazılarının birçok patojene karşı etkili olduğu gösterilmiştir (Punja ve Grogan, 1982; Elmer, 1989; Gottstein ve Kuc, 1989; Cherif ve Belanger, 1992; Ziv ve Zitter, 1992; Punja ve Gaye, 1993; Palmer ve ark., 1997; Olivier ve ark., 1998; Mecteau ve ark., 2002; Palou ve ark., 2002; Mills ve ark., 2004; Bi ve ark., 2006; Orbovic ve ark., 2008; Arslan, 2015; Türkkan ve Erper, 2015; Jabnoun-Khiareddine ve ark., 2016).

$\mathrm{Bu}$ çalışmada, Ordu ili kivi bahçelerinde kök çürüklüğüne neden olan $F$. oxysporum, $F$. solani ve $R$. solani AG 4'e karşı amonyum, kalsiyum, potasyum ve sodyumun bazı organik ve inorganik tuzları ve sentetik fungisit olarak Captan'ın etkinlikleri in vitro denemeler, toprak ve kök testleri ile ilk kez çalışılmıştır. 
Çizelge 3. Fusarium oxysporum, Fusarium solani ve Rhizoctonia solani AG 4'e karşı organik ve inorganik tuzlar ile Captan'in fungistatik ve/veya fungisidal etkileri

\begin{tabular}{|c|c|c|c|c|c|c|c|c|}
\hline \multirow{3}{*}{ Bileşikler } & \multirow{3}{*}{ Funguslar } & \multicolumn{7}{|c|}{ Konsantrasyon $(\%, w / v)$} \\
\hline & & 0.025 & 0.05 & 0.1 & 0.25 & 0.5 & 1.0 & 2.0 \\
\hline & & Gün* & Gün & Gün & Gün & Gün & Gün & Gün \\
\hline \multirow{3}{*}{ A. bikarbonat } & F. oxysporum & $\mathrm{B}$ & $\mathrm{B}$ & $\mathrm{B}$ & $\mathrm{B}$ & 8 & MFC & MFC \\
\hline & F. solani & B & B & B & B & 8 & MFC & MFC \\
\hline & R. solani & B & B & B & MFC & MFC & MFC & MFC \\
\hline \multirow{3}{*}{ A. karbonat } & F. oxysporum & $\mathrm{B}$ & $\mathrm{B}$ & $\mathrm{B}$ & $\mathrm{B}$ & 8 & MFC & MFC \\
\hline & F. solani & B & B & B & B & 8 & MFC & MFC \\
\hline & R. solani & B & B & B & MFC & MFC & MFC & MFC \\
\hline \multirow{3}{*}{ P. benzoat } & F. oxysporum & $\mathrm{B}$ & $\mathrm{B}$ & $\mathrm{B}$ & $\mathrm{B}$ & $\mathrm{B}$ & 8 & 9 \\
\hline & F. solani & B & B & B & B & B & 9 & 9 \\
\hline & R. solani & B & B & B & B & B & B & B \\
\hline \multirow{3}{*}{ P. karbonat } & F. oxysporum & $\mathrm{B}$ & $\mathrm{B}$ & $\mathrm{B}$ & $\mathrm{B}$ & B & $\mathrm{B}$ & B \\
\hline & F. solani & B & B & B & B & B & B & B \\
\hline & R. solani & B & B & B & B & B & 4 & 5 \\
\hline \multirow{3}{*}{ P. sorbat } & F. oxysporum & B & B & B & 8 & 8 & 9 & 9 \\
\hline & F. solani & B & B & 7 & 7 & 8 & 8 & 9 \\
\hline & R. solani & B & B & B & MFC & MFC & MFC & MFC \\
\hline \multirow{3}{*}{ S. benzoat } & F. oxysporum & B & B & B & $\mathrm{B}$ & 8 & 9 & 9 \\
\hline & F. solani & B & B & B & B & 9 & 9 & MFC \\
\hline & R. solani & B & B & B & B & MFC & MFC & MFC \\
\hline \multirow{3}{*}{ S. bikarbonat } & F. oxysporum & B & B & B & B & B & $\mathrm{B}$ & $\mathrm{B}$ \\
\hline & F. solani & B & B & B & B & B & B & B \\
\hline & R. solani & B & B & B & B & B & B & 3 \\
\hline \multirow{3}{*}{ S. karbonat } & F. oxysporum & B & B & B & B & B & B & $\mathrm{B}$ \\
\hline & F. solani & B & B & B & B & B & B & B \\
\hline & R. solani & B & B & B & B & B & 3 & 3 \\
\hline \multirow{3}{*}{ S. metabisülfit } & F. oxysporum & B & B & B & MFC & MFC & MFC & MFC \\
\hline & F. solani & B & B & $\mathrm{B}$ & MFC & MFC & MFC & MFC \\
\hline & R. solani & B & B & MFC & MFC & MFC & MFC & MFC \\
\hline \multirow{3}{*}{ Captan } & F. oxysporum & B & $\mathrm{B}$ & B & $B$ & $\mathrm{~B}$ & ND & MFC \\
\hline & F. solani & B & B & B & B & B & MFC & MFC \\
\hline & R. solani & B & B & B & B & B & 7 & MFC \\
\hline
\end{tabular}

*Tamamen engelleme gerçekleșen petrilerdeki fungal inokulum taze besi ortamına aktarıldıktan sonra petriyi kaplaması için geçen gün sayısı, $\mathrm{B}=$ Belirlenemedi

Çizelge 4. Toprak testinde Fusarium oxysporum, Fusarium solani ve Rhizoctonia solani AG 4'ün miselyal gelişimleri üzerine organik ve inorganik tuzlar ile Captan'ın etkisi

\begin{tabular}{|c|c|c|c|c|c|}
\hline \multirow{2}{*}{ Bileşikler } & \multirow{2}{*}{$\begin{array}{c}\text { Konsantrasyon } \\
(\%, w / v)\end{array}$} & \multicolumn{4}{|c|}{$\%$ Engelleme } \\
\hline & & F. oxysporum & F. solani & R. solani $\mathrm{AG} 4$ & \\
\hline \multirow{2}{*}{ A. bikarbonat } & 0.75 & $89.66 \mathrm{ab}^{*}$ & 82.91 b-d & 100.00 & \\
\hline & 1 & $95.60 \mathrm{a}$ & $96.95 \mathrm{a}$ & 100.00 a & a \\
\hline \multirow{2}{*}{ A. karbonat } & 0.75 & $83.61 \mathrm{ab}$ & 92.86 a & 100.00 & $\mathrm{a}$ \\
\hline & 1 & $92.89 \mathrm{a}$ & $98.80 \mathrm{a}$ & 100.00 & a \\
\hline \multirow{2}{*}{ P. benzoat } & 0.25 & $40.55 \mathrm{~d}$ & $49.56 \mathrm{f}$ & 21.44 & $\mathrm{e}$ \\
\hline & 0.5 & $52.11 \mathrm{~cd}$ & $55.38 \mathrm{f}$ & 26.55 & $\mathrm{e}$ \\
\hline \multirow{2}{*}{ P. sorbat } & 0.25 & $64.85 \mathrm{c}$ & $78.13 \mathrm{~cd}$ & 76.86 & $\mathrm{~d}$ \\
\hline & 0.5 & $87.94 \mathrm{ab}$ & $92.74 \mathrm{ab}$ & $100.00 \quad \mathrm{a}$ & $\mathrm{a}$ \\
\hline \multirow[t]{2}{*}{ S. benzoat } & 0.25 & $47.75 \mathrm{~d}$ & 59.81 ef & 83.01 & $\mathrm{~cd}$ \\
\hline & 0.5 & $61.58 \mathrm{c}$ & 86.35 a-d & 100.00 & $\mathrm{a}$ \\
\hline \multirow{2}{*}{ S. metabisülfit } & 0.1 & $79.84 \mathrm{~b}$ & $72.93 \mathrm{de}$ & $89.33 \mathrm{k}$ & $\mathrm{bc}$ \\
\hline & 0.25 & $94.87 \mathrm{a}$ & $91.22 \mathrm{a}-\mathrm{c}$ & 100.00 a & $\mathrm{a}$ \\
\hline \multirow[t]{2}{*}{ Captan } & 0.25 & $90.15 \mathrm{ab}$ & $93.50 \mathrm{ab}$ & $95.23 \mathrm{a}$ & $a b$ \\
\hline & 0.5 & $96.21 \mathrm{a}$ & $97.69 \mathrm{a}$ & 98.89 a & $\mathrm{a}$ \\
\hline Kontrol & 0 & $0 \mathrm{e}$ & $0 \quad \mathrm{~g}$ & $0 \mathrm{f}$ & $\mathrm{f}$ \\
\hline
\end{tabular}

\footnotetext{
*Aynı sütünda yer alan ve aynı harfle gösterilen değerler için Tukey-HSD P $<0.05$ ’e göre fark yoktur
} 
Çizelge 5. Kök testinde Fusarium oxysporum, Fusarium solani ve Rhizoctonia solani AG 4'e karşı organik ile inorganik tuzlar ve Captan'ın etkisi

\begin{tabular}{|c|c|c|c|c|c|}
\hline $\begin{array}{l}\text { Bileşikler } \\
(\%, \mathrm{w} / \mathrm{v})\end{array}$ & Funguslar & Kök çürüklüğg̈ü & $\begin{array}{l}\text { Kök uzunluğu } \\
(\mathrm{cm})\end{array}$ & $\begin{array}{l}\text { Kök yaş } \\
\text { ağırlı̆ğ } \\
\text { (g) }\end{array}$ & $\begin{array}{l}\text { Kök kuru } \\
\text { ağırlığ } \\
\text { (g) }\end{array}$ \\
\hline Kontrol (Negatif) & - & $0.67 \mathrm{f}^{*}$ & $23.73 \mathrm{a}$ & $9.64^{\mathrm{a}}$ & 1.75 \\
\hline \multirow{3}{*}{ Kontrol (Pozitif) } & F. oxysporum & 4.33 a-c & $6.03 \mathrm{f}-\mathrm{h}$ & 0.71 & 0.10 \\
\hline & F. solani & $5.00 \mathrm{a}$ & $0.83 \mathrm{~h}$ & 0.17 & 0.02 \\
\hline & R. solani & $4.67 \mathrm{ab}$ & $4.83 \mathrm{gh}$ & 0.59 & 0.23 \\
\hline \multirow{3}{*}{ A. bikarbonat (1.0) } & F. oxysporum & 3.00 b-e & 17.83 a-c & 7.60 & 1.40 \\
\hline & F. solani & 3.33 a-e & $12.00 \mathrm{c}-\mathrm{g}$ & 3.59 & 0.65 \\
\hline & R. solani & 3.00 b-e & $20.50 \mathrm{ab}$ & 7.16 & 1.24 \\
\hline \multirow{3}{*}{ A. karbonat $(0.75)$} & F. oxysporum & 3.67 a-d & $12.07 \mathrm{c}-\mathrm{g}$ & 2.82 & 0.39 \\
\hline & F. solani & $3.00 \quad b-e$ & $15.37 \mathrm{~b}-\mathrm{e}$ & 3.58 & 0.55 \\
\hline & R. solani & 3.33 a-e & 13.80 b-f & 4.69 & 0.79 \\
\hline \multirow{3}{*}{ P. benzoate $(0.25)$} & F. oxysporum & $2.33 \mathrm{~d}-\mathrm{f}$ & 15.47 b-d & 6.78 & 01.11 \\
\hline & F. solani & $2.33 \mathrm{~d}-\mathrm{f}$ & 16.90 a-d & 7.40 & 1.38 \\
\hline & R. solani & 3.33 a-e & $9.53 \mathrm{c}-\mathrm{g}$ & 2.78 & 0.32 \\
\hline \multirow{3}{*}{ P. sorbat $(0.25)$} & F. oxysporum & $2.00 \mathrm{~d}-\mathrm{f}$ & 14.83 b-e & 3.38 & 0.62 \\
\hline & F. solani & $2.67 \mathrm{c}-\mathrm{e}$ & 13.49 b-f & 6.12 & 1.27 \\
\hline & R. solani & 3.33 a-e & $12.07 \mathrm{c}-\mathrm{g}$ & 4.84 & 0.69 \\
\hline \multirow{3}{*}{ S. benzoat $(0.25)$} & F. oxysporum & 4.33 a-c & 7.53 e-h & 1.54 & 0.29 \\
\hline & F. solani & 3.67 a-d & $9.13 \mathrm{~d}-\mathrm{g}$ & 3.19 & 0.56 \\
\hline & R. solani & 3.00 b-e & $12.13 \mathrm{c}-\mathrm{g}$ & 3.60 & 0.45 \\
\hline \multirow{3}{*}{ S. metabisülfit $(0.1)$} & F. oxysporum & $2.00 \mathrm{~d}-\mathrm{f}$ & 15.57 b-d & 3.04 & 0.55 \\
\hline & F. solani & $1.67 \mathrm{ef}$ & $14.13 \mathrm{~b}-\mathrm{e}$ & 4.53 & 0.71 \\
\hline & R. solani & $2.00 \mathrm{~d}-\mathrm{f}$ & 16.47 a-d & 4.74 & 0.79 \\
\hline \multirow{3}{*}{ Captan (0.25) } & F. oxysporum & 1.67 ef & 15.03 b-e & 3.19 & 0.46 \\
\hline & F. solani & $2.00 \mathrm{~d}-\mathrm{f}$ & $9.67 \mathrm{~d}-\mathrm{g}$ & 2.90 & 0.48 \\
\hline & R. solani & $3.00 \mathrm{~b}-\mathrm{e}$ & $12.27 \mathrm{c}-\mathrm{g}$ & 5.67 & 1.10 \\
\hline
\end{tabular}

*Aynı sütünda yer alan ve aynı harfle gösterilen değerler için Tukey-HSD P $<0.05$ 'e göre fark yoktur

${ }^{a}$ İstatiksel olarak önemsiz bulunmuştur $(\mathrm{P}>0.05)$

In vitro'da $\% \quad 2$ konsantrasyonda, çalışmada kullanılan 22 bileşikten sadece 6 (amonyum bikarbonat, amonyum karbonat, potasyum sorbat, sodyum benzoat, sodyum metabisülfit ve Captan)'sı her üç fungusun miselyal gelişmesini tamamen engellemiştir. Potasyum benzoat $F$. oxysporum ve $F$. solani'nin miselyal gelişmesini tamamen engellerken, potasyum karbonat, sodyum bikarbonat ve sodyum karbonat $R$. solani AG 4'ün misel gelişimini tümüyle engellemiştir. Birkaç istisna dışında amonyum asetat, kalsiyum (asetat, propionat, silikat ve sitrat) ve sodyum (asetat, format, propionat, sitrat, süksinat ve tartarat) bileşikleri $R$. solani AG 4'ün miselyal gelişmesini iki Fusarium türüne kıyasla daha kuvvetli bir şekilde engellemiştir. Hatta kalsiyum propiyonat yukarıda tamamen engelleme gerçekleștiren 9 organik ve inorganik tuzdan istatiksel olarak farklı bulunmamıştır $(\mathrm{P}<0.05)$. Önceki çalışmalardan elde edilen sonuçlar bizim bulgularımız ile paralellik göstermektedir. Mecteau ve ark., (2002, 2008) sodyum benzoatın ve sodyum metabisülfitin 0.2 M (\%7.6) konsantrasyonlarında $F$. sambicinum ve $F$. solani var. coereuleum'un miselyal gelişmesini tamamen engellediğini bildirmiştir. Önceki çalışma ile aynı konsantrasyondaki sodyum metabisülfitin
Helminthosporium solani'nin hem miselyal gelişmesi hem de konidi oluşumunu ve konidi çimlenmesini tamamen engellediği belirlenmiştir (Hervieux ve ark., 2002). Hatta daha düşük konsantrasyonda $(0.02 \mathrm{M})$ bile sodyum metabisülfit ve amonyum karbonatın Penicillium italicum'un miselyal gelişimini ve sporulasyonunu engellediği bildirilmiştir (Latifa ve ark., 2011). Arslan ve ark. (2009) F. oxysporum f. sp. melonis, M. phaseolina, $R$. solani ve $S$. sclerotiorum'un miselyal gelişmesinin amonyum bikarbonat ve potasyum sorbatın \% 0.05-0.6 konsantrasyonlarında tamamen engellediği, ancak potasyum benzoatın çalışmada kullandıkları en yüksek konsantrasyonda (\% 2) bile $R$. solani'yi engelleyemediğini tespit etmişlerdir. Türkkan ve Erper (2015) sodyum benzoat, sodyum metabisülfit ve Captan'ın \% 2 konsantrasyonda $F$. equiseti, $F$. proliferatum, $F$. semitectum, $F$. solani $\mathrm{f}$. sp. phaseoli, $F$. verticillioides, M. phaseolina, $R$. solani ve $S$. rolfsii'nin miselyal gelişmesini tamamen engellediğini, ancak sodyum karbonat ve sodyum bikarbonatın Fusarium türlerini yaklaşık \% $37-90$ arasında değişen oranlarda engellediğini bildirmişlerdir. Ancak aynı çalışmada sodyum karbonatın $M$. phaseolina, $R$. solani ve $S$. rolfsii'yi tamamen 
engellerken, sodyum bikarbonatın $S$. rolfsii hariç tamamen engelleme sağlamamasına karşın, diğer iki fungusa karşı engelleyici etkisinin oldukça yüksek olduğu ve istatistiki olarak sodyum karbonattan farklı olmadığını tespit etmişlerdir. Amonyum asetat, kalsiyum (asetat, propionat ve silikat) ve sodyum (asetat, format, sitrat, süksinat ve tartarat) tuzlarının $I$. liriodendri'nin miselyal gelişimini yaklaşık \% 2-35 gibi düşük oranlarda engellediği bildirilmiştir (Türkkan, 2015).

Çalışmada $F$. oxysporum, $F$. solani ve $R$. solani AG 4 için Captan'ın $\mathrm{ED}_{50}$ değeri amonyum bikarbonat, amonyum karbonat ve sodyum metabisülfitten düşük olmasına karşın, MIC ve MFC değerleri \% 1-2 arasında bulunmuştur. $F$. oxysporum, $F$. solani ve $R$. solani AG 4'e karşı sodyum metabisülfitin fungistatik ve fungisidal etkileri sirasiyla $\% \quad 0.25, \quad 0.25$ ve 0.1 olarak belirlenmiştir. Önceki çalı̧̧malarda bizim sonuçlarımızla uyumlu olup, Nisa ve ark. (2011) Captan'1n \% 0.2 konsantrasyonunun $F$. oxysporum'un tamamen engellenmesi için yeterli olmadığını belirtmişlerdir. Türkkan ve Erper (2015) Captan'ın $\mathrm{ED}_{50}$ değerinin çalışmadaki sekiz fungusa karşı sodyum metabisülfit ve diğer sodyum bileşiklerinden daha düşük bir değere sahip olduğunu, ancak fungistatik etkisinin sodyum metabisülfitten oldukça yüksek bir konsantrasyonda ortaya çıktığını belirtmiştir. Talibi ve ark. (2011) P. italicum'a karşı kullandıkları 28 organik asit ve tuz içerisinde sodyum metabisülfitin en düşük $\mathrm{ED}_{50}$, MIC ve MFC değerlerine sahip olup, sirasıyla 1.69 (\% 0.03$), 5(\% 0.1)$ ve 5 (\% 0.1$)$ mM olarak belirlemişlerdir. Benzer olarak Arslan (2015) kükürt içeren 6 tuz içerisinde $F$. culmorum, $F$. nivale, $F$. solani, $M$. phaseolina, $R$. solani ve $S$. sclerotiorum'a karșı en düşük $\mathrm{ED}_{50}, \mathrm{MIC}$ ve $\mathrm{MFC}$ değerlerinin sodyum metabisülfite ait olduğunu ve tüm funguslar için \% $0.03-0.12, \% 0.05-0.17$ ve \% 0.1-0.2 arasında değiştiğini bildirmiştir. Türkkan $(2013,2015) F$. oxysporum f. sp. cepae ve Ilyonectria liriodendri için sodyum metabisülfitin $\mathrm{ED}_{50}$, $\mathrm{MIC}$ ve $\mathrm{MFC}$ değerlerinin çalışmada kullanılan amonyum karbonat, amonyum bikarbonat ve diğer tuzlardan daha düşük olduğunu belirtmiştir. Çalışmamızda da sodyum metabisülfit her üç fungusa karşı diğer bileşiklerden daha yüksek bir fungitoksik etki göstermiştir. Amonyum karbonat ve bikarbonat için MIC ve MFC değerleri $F$. oxysporum ve $F$. solani için sirasıyla $\% 0.5$ ve 1 ve $R$. solani AG 4 için ise \% 0.25 ve 0.25 olarak tespit edilmiştir. Amonyum karbonat ve bikarbonatın \% $0.5^{\prime}$ lik konsantrasyonlarında her iki Fusarium türü de 8 gün içinde gelişmiş, fakat \% 0.25 konsantrasyonu $R$. solani için fungisidal olarak belirlenmiștir. Ancak potasyum karbonat, sodyum karbonat ve sodyum bikarbonatın \% 1 veya 2 konsantrasyonlarında $R$. solani AG 4, 3-5 gün içerisinde gelişmiştir. Palou ve ark. (2001) sodyum karbonat ve bikarbonatın \% 4 konsantrasyonda $P$. italicum'a fungisidal olmaktan daha çok fungistatik etki gösterdiğini rapor etmişlerdir. Arslan ve ark. (2009) amonyum bikarbonat dışında diğer karbonat ve bikarbonat (potasyum ve sodyum)'ların çalışmada kullandıkları en yüksek konsantrasyon olan $\% 2$ 'de bile $F$. oxysporum f. sp. melonis, M. phaseolina ve $R$. solani'ye karşı fungisidal etki göstermediklerini belirtmişlerdir. Benzer olarak aynı konsantrasyonda potasyum sorbatın $F$. oxysporum f. sp. melonis ve $M$. phaseolina'ya karş1 fungistatik etki gösterdiğini ve sırasıyla fungusların 9 ve 4 gün içerisinde geliştiğini tespit etmişlerdir. Mevcut çalışmada potasyum sorbat \% 0.1 ve 0.25 gibi düşük konsantrasyonlarda $F$. solani ve $F$. oxysporum için fungistatik etki gösterirken $R$. solani için \% 0.25 'te fungisidal etki gösterdiği belirlenmiştir. Ancak potasyum sorbat ve potasyum benzoatın \% 2'lik konsantrasyonlarında $F$. oxysporum ve $F$. solani 9 gün içinde gelişmesine rağmen, sodyum benzoatın aynı konsantrasyonunun $F$. oxysporum için etkisi benzerken $F$. solani için fungisidal olduğu saptanmıştır.

Organik ve inorganik tuzlar ile Captan'ın \% 2 konsantrasyonunda $\mathrm{pH}$ değerlerinin birbirinden farkl1 olup, 4.80-10.65 arasında değiştiği belirlenmiştir. En düşük $\mathrm{pH}$ değerlerine sahip kalsiyum asetat (4.80) ve sodyum metabisülfit (4.84)'in funguslar üzerine etkilerinin farklı olup, sodyum metabisülfit her üç fungusun miselyal gelişmesini tamamen engellerken, kalsiyum asetatın $F$. solani'ninki üzerine hiç bir engelleyici etkisi olmadığı, hatta tuz eklenmemiş kontrol petrilerinden istatistiki olarak farksız olduğu bulunmuştur $(\mathrm{P}<0.05)$. Önceki çalışmalar ile sonuçlarımız benzerlik göstermektedir. Türkkan ve Erper (2014) benzer pH değerlerine sahip olan sodyum metabisülfit (pH: 4.80)'in $F$. oxysporum f. sp. cepae'nın miselyal gelişmesini \% 2 konsantrasyonda tamamen engellediğini, sodyum fosfat monobazik (pH: 4.85)'in ise fungusun miselyal gelişmesini negatif olarak etkilemediğini, aksine uygulama görmemiş kontrole kıyasla artırdığını belirtmektedir. Benzer olarak Türkkan (2015) \% 2 konsantrasyonda sodyum metabisülfitin I. liriodendri'yi tamamen engellediğini, ancak kalsiyum asetatın kontrol petrilerine kıyasla yaklaşık \% 6 oranında bir engelleme sağladığını tespit etmiştir. Sodyum metabisülfitin toksik etkisinin esasen asidik koşullarda oluşan sülfüroz asit ve bisülfit iyonlarından kaynaklandığı bildirilmektedir (Russell, 2005). Dolayısıyla organik ve inorganik tuzların $\mathrm{pH}$ değerlerinin onların toksik etkilerinde sinırlı bir role sahip olduğu bildirilmiştir (Mecteau ve ark., 2002).

Toprak testlerinde amonyum karbonat ve bikarbonat konsantrasyonları hariç benzer konsantrasyon (\% 0.25)'da kullanılan Captan, potasyum benzoat, potasyum sorbat, sodyum benzoat ve sodyum metabisülfit arasında funguslara karşı en etkili olanlar sodyum metabisülfit ve Captan olarak belirlenmiştir. $\mathrm{Bu}$ bulgular Arslan ve ark. (2006) tarafindan da doğrulanmaktadır. Aynı araştırıcılar, toprak testlerinde $\%$ 0.6'lik potasyum sorbatı, $F$. oxysporum f. sp. melonis, M. phaseolina ve $R$. solani'yi tamamen engellediğini, ancak amonyum bikarbonatın çalışmada kullandıkları en yüksek konsantrasyon (\% 2)'da bunu gerçekleştirdiğini tespit etmişlerdir. Arslan (2015), 
toprak testlerinde potasyum ve sodyum metabisülfitin \% 0.4 konsantrasyonda $F$. culmorum, $F$. nivale, $F$. solani, M. phaseolina, $R$. solani ve $S$. sclerotiorum'u tamamen engellediğini belirlemiştir. Benzer olarak Türkkan ve Erper (2015) Captan, sodyum benzoat ve sodyum metabisülfitin $\% \quad 0.1$ ve daha yüksek konsantrasyonlarında $F$. equiseti, $F$. proliferatum, $F$. semitectum, $F$. solani $\mathrm{f}$. sp. phaseoli, $F$. verticillioides, M. phaseolina, $R$. solani ve $S$. rolfsii'nin misel gelişmelerini tamamen engellediğini belirlemişlerdir.

Kök testlerinde en etkili bileşiklerin sodyum metabisülfit ve Captan uygulamaları olup, $F$. oxysporum, $F$. solani ve $R$. solani AG 4'ün kivi fidanlarında neden olduğu kök çürüklüğü şiddetini inokuleli kontrol bitkilerine kıyasla önemli oranda azalttığ1 belirlenmiştir $(\mathrm{P}<0.05)$. Diğerlerinin kök çürüklüğüne karşı etkilerinin genellikle funguslara göre farklılık gösterdiği tespit edilmiştir. İnokuleli kontrole kıyasla, fidanların kök uzunluğu üzerine amonyum karbonat, amonyum bikarbonat, potasyum benzoat, potasyum sorbat, sodyum benzoat, sodyum metabisülfit ve Captan'ın hastalık etmenlerine karşı etkili olduğu belirlenmiştir. Ancak tüm uygulamalar kök yaş ve kuru ağırlığı bakımından istatistiki olarak önemsiz bulunmuştur $(\mathrm{P}>0.05)$. Bu sonuçlar önceki çalıșmaların bulguları ile uyumludur. Sodyum metabisülfit uygulamasinın $F$. oxysporum, $F$. semitectum ve $F$. moniliforme'nin yerfıstıklarında neden olduğu enfeksiyonu etkili bir şekilde kontrol ettiği bildirilmiştir (Vir ve Vaidya, 1987). Yine bir başka araştırıcı patateslerde kuru çürüklüğe neden olan $F$. sambucinum'a karşı sodyum metabisülfitin koruyucu etkiye sahipken, alüminyum kloritin tedavi edici özellikte olduğunu tespit etmiştir (Mecteau ve ark., 2002). Arslan (2015) sodyum metabisülfit (\% 0.5) ve potasyum metabisülfit ( $\% 0.75$ )'in buğday ve fasulye yapraklarına uygulanması ile pas hastalığı etmenleri Puccinia triticina ve Uromyces appendiculatus'un neden olduğu püstülleri sırasıyla yaklaşık olarak \% 6268 ve \% 68-70 oranında azalttığını belirtmiştir. Ayrıca Türkkan, (2015) kivi fidanları üzerinde yaptığı fitotoksisite çalışmalarında potasyum benzoat, potasyum sorbat, sodyum benzoat ve sodyum metabisülfitin \% 0.25 konsantrasyon uygulamalarının herhangi bir fitotoksiteye neden olmazken, \% 2 amonyum bikarbonat ve \% 1.5 amonyum karbonat uygulamalarının fitotoksiteye neden olduğunu tespit etmiştir.

\section{Sonuç}

$\mathrm{Bu}$ çalışmadan elde edilen bulgular kivilerde kök çürüklüğüne neden olan $F$. oxysporum, $F$. solani ve $R$. solani AG 4'ün kontrolünde organik ve inorganik bazı tuzların kullanılabileceğini göstermiş̧ir. Çalışmada kullanılan 21 organik ve inorganik tuz arasindan amonyum bikarbonat, amonyum karbonat, potasyum benzoat, potasyum sorbat, sodyum benzoat ve sodyum metabisülfit in vitro'da funguslara karşı etkili bulunmuş, hatta çalışmada kullanılan sentetik fungisit Captan da olduğu gibi amonyum karbonat, amonyum bikarbonat ve sodyum metabisülfitin fungistatik ve/veya fungisidal etki gösterdikleri belirlenmiştir. Toprak testlerinde Captan ve sodyum metabisülfit, amonyum karbonat ve bikarbonattan daha düşük konsantrasyonda kullanılmasına karşın her üç fungusa karşı etkili oldukları görülmüştür. $\mathrm{Bu}$ bulgular kök testlerinde de doğrulanmış olup, sodyum metabisülfit ve Captan fungusların neden olduğu kök çürüklüğü şiddetini inokuleli kontrol bitkilerine kıyasla önemli ölçüde azaltmıştır. Ancak kök uzunluğu üzerine tüm uygulamaların hastalık etmenlerine karşı etkili olduğu ve inokuleli kontrol bitkilerinden farklı grupta yer aldığ görülmüştür.

Ülkemizde kivide kök çürüklüğü hastalıkları yeni yeni tanımlanmakta olup, henüz bu hastalıklara karşı ruhsatlı fungisitler bulunmamaktadır. $\mathrm{Bu}$ çalışmada kullanılan organik ve inorganik tuzların çevre ve insan sağlığı üzerine toksik bir etkisinin az veya hiç olmaması ve ayrıca şu ana kadar bunlara karşı patojenlerde henüz bir direnç tespit edilmemesinden dolayı, kontrolü oldukça zor olan kök çürüklüğü hastalıklarının mücadelesinde sentetik fungisitlere karşı etkili bir alternatif olarak karşımıza çıkmaktadır. Ancak bu tuzlar tavsiye edilmeden önce hem doğal çevre koşulları üzerine etkileri (toprak pH'sı) ve farklı konukçu patojen interaksiyonları araştırılmalıdır. Ayrıca bu tuzların daha sonraki çalışmalarda kök çürüklüğü patojenleri ile bulaşık kivi bahçelerinde yürütülecek denemeler ile de değerlendirilmesi gerekir.

\section{Teșekkür}

Bu çalışma Ordu Üniversitesi Bilimsel Araştırmalar Birimi TF-1454 Proje numarası ile desteklenmiştir.

\section{Kaynaklar}

Agrios, G.N., 2005. Plant pathology, 5th edition. Elsevier academic press, San Diego, USA, $948 \mathrm{~s}$.

Ak, K., Saruhan, İ., Tuncer, C., Akyol, H., Kılıç, A., 2011. Ordu ili kivi bahçelerinde yazıcıböcek (Coleoptera: Scolytidae) türlerinin tespiti ve zarar oranları. Türkiye Entomoloji Bülteni 1 (4):229-234.

Akıllı, S., Serçe, Ç.U., Katırcioğlu, Y.K., Karakaya, A., Maden, S., 2011. Involvement of Phytophthora citrophthora in kiwifruit decline in Turkey. Journal of Phytopathology 159:579-581.

Alaniz S, Abad-Campos P, García-Jiménez J, Armengol, J., 2011. Evaluation of fungicides to control Cylindrocarpon liriodendri and Cylindrocarpon macrodidymum in vitro and their effect during the rooting phase in the grapevine propagation process. Crop Protection 30(4):489-494.

Anonim, 1999. https:// bio.kiwifruit.it.1999.pdf (Erişim Tarihi 24.11.2016).

Arslan, U., Ilhan, K., Karabulut, O.A., 2006. Evaluation of food additives and low-toxicity compounds for the control of bean rust and wheat leaf rust. Journal of Phytopathology 154:534-541. 
Arslan, U., Kadir, I., Vardar, C., Karabulut, O.A., 2009. Evaluation of antifungal activity of food additives against soilborne phytopathogenic fungi. World Journal of Microbiology and Biotechnology, 25: 537-543.

Arslan, U., Ilhan, K., Karabulut, O.A., 2013. Evaluation of the use of ammonium bicarbonate and oregano (Origanum vulgare ssp. hirtum) extract on the control of apple scab. Journal Phytopathol 161:382-388.

Arslan, U., 2015. Evaluation of antifungal activity of sulfurcontaining salts against phytopathogenic fungi. Fresenius Environmental Bulletin 24(5a):1879-1886.

Baştaş, K., Karakaya, A., 2012. First report of bacterial canker of kiwifruit caused by Pseudomonas syringae pv. actinidiae in Turkey. Plant Disease 96(3):452.

Bi, Y., Tian, S.P., Guo, Y.R., Ge, Y.H., Qin, G.Z., 2006. Sodium silicate reduces postharvest decay on Hami melons: induce resistance and fungistatic effects. Plant Disease 90: 279-83.

Brook, P.J., 1986. Diseases of kiwifruit. In 'Kiwifruit: science and management'. (Eds IJ Warrington, GC Weston). New Zealand, Ray Richards Publisher pp 420-428.

Campanella, V., Ippolito, A., ve Nigro, F., 2002. Activity of calcium salts in controlling Phytophthora root rot of citrus. Crop Protection 21: 751-756.

Cherif, M., Belanger, R.R., 1992. Use of potassium silicate amendments in recirculating nutrient solutions to suppress Pythium ultimum on long English cucumber. Plant Disease 76: 1008-1011.

Conn, K.E., Gubler, W.D., Mircetich, S.M., Hasey, J.K., 1991. Pathogenicity and relative virulence of nine Phytophthora spp. from kiwifruit. Phytopathology, 81: 974-979.

Corral, L.G., Post, L.S., Montville, T.J., 1988. Antimicrobial activity of sodium bicarbonate. Journal Food Science 53: 981-982.

DePasquale, D.A., El-Nabarawy, A., Rosen, J.D., Montville, T.J., 1990. Ammonium bicarbonate inhibition of mycotoxigenic fungi and spoilage yeasts. Journal of Food Protection 4: 282-350.

Di Marco, S., Calzarano, F., Gams, W., Cesari, A., 2000. A new wood decay of kiwifruit in Italy. New Zealand Journal of Crop and Horticultural Science 28: 69-73.

Di Marco, S., Osti, F., Spada, G., 2003. The wood decay of kiwifruit and first control measures. Acta Horticulturae 610:291-294.

Di Marco, S., Calzarano, F., Osti, F., Mazzullo, A., 2004. Pathogenicity of fungi associated with a decay of kiwifruit. Australasian Plant Pathology, 33: 337-342.

Elena, K., Paplomatas, E.J. 2002. First report of Fomitiporia punctata infecting kw1fruit. Plant Disease, 86(10): 1176.

Elmer, W.H. 1989. Effect of chloride and nitrogen form on growth of asparagus infected by Fusarium spp. Plant Disease 73:736-740.

Erper, İ., Tunali, B., Agusti-Brisach, C., Armengol, J., 2011 a. First report of Cylindrocarpon liriodendri on kiwifruit in Turkey. Plant Disease 95:76.

Erper, İ, Türkkan, M, Karaca, G.H., Kılıç, G., 2011 b. Evaluation of in vitro antifungal activity of potassium bicarbonate on Rhizoctonia solani AG 4 HG-I, Sclerotinia sclerotiorum and Trichoderma sp. African Journal of Biotechonology 10(43): 8605-8612.

Erper, İ., Agustí-Brisach, C., Tunali, B., Armengol, J., 2013. Characterization of root rot disease of kiwifruit in the Black Sea region of Turkey. European Journal of Plant Pathology 136:291-300.
Fan, C.M., Xiong, G.R., Qi, P., Ji, G.H., He, Y.Q., 2008. Potential biofumigation effects of Brassica oleracea var. caulorapa on growth of fungi. Journal of Phytopathology, 156:321-325.

FAO, 2016. http://faostat3.fao.org/download/Q/QC/E (Erişim Tarihi: 10.10.2016).

Farih, A., Menge, J.A., Tsao, P.H., Ohr, H.D., 1981. Metalaxyl and efosite aluminum for control of Phytophthora gummosis and root rot on citrus. Plant Disease, 65:654-657.

FDA, 2016. http://www.fda.gov/IngredientsPackaging (ErişimTarihi: 01.11.2016).

Gottstein, H.D., Kuc, J., 1989. Induction of systemic resistance to anthracnose in cucumber by phosphates. Phytopathology 79: 176-179.

Güncan, A., 2015. Current status of the kiwifruit pests in Turkey. Acta Horticulture, 1096:371-376.

Hervieux, V., Yaganza, E.S., Arul, J., Tweddell, R.J., 2002. Effect of organic and inorganic salts on the development of Helminthosporium solani, the causal agent of potato silver scurf. Plant Disease, 86: 1014-1018.

Jabnoun-Khiareddine, H., Abdallah, R., El-Mohamedy, R., Abdel-Kareem, F., Gueddes-Chahed, M., Hajlaoui, A., Daami-Remadi, M., 2016. Comparative efficacy of potassium salts against soil-borne and air-borne fungi and their ability to suppress tomato wilt and fruit rots. Journal of Microbial and Biochemical Technology 8(2): 45-55.

Karakaya, A., 2001. First report of infection of kiwifruit by Pestalotiopsis sp. in Turkey. Plant Disease 85(9):1028.

Kurbetli, İ., Ozan, S., 2013. Occurrence of Phytophthora root and stem rot of kiwifruit in Turkey. Journal of Phytopathology 161: 887-889.

Krausz, J.P., Caldwell, J.D., 1987. Cylindrocladium root rot of kiwifruit. Plant Disease 71: 374-375.

Latifa, A., Idriss, T., Hassan, B., Amine, S.M., El Hassane, B., Abdellah, A.B.A., 2011. Effects of organic acids and salts on the development of Penicillium italicum: the causal agent of citrus blue mold. Plant Pathology J 10: 99-107.

Latorre, B.A., Alvarez, C., Ribeiro, O.K., 1991. Phytophthora root rot of kiwifruit in Chile. Plant Disease 75, 949-952.

Mecteau, M.R., Arul, J., Tweddell, R.J., 2002. Effect of organic and inorganic salts on the growth and development of Fusarium sambucinum, a causal agent of potato dry rot. Mycological Research, 106: 688-696.

Mecteau, M.R., Arul, J., Tweddell, R.J., 2008. Effect of different salts on the development of Fusarium solani var. coeruleum, a causal agent of potato dry rot. Phytoprotection, 89: 1-6.

Mills, A.A.S., Platt, H.W., Hurta, R.A.R., 2004. Effect of salt compounds on mycelial growth, sporulation and spore germination of various potato pathogens. Postharvest Biology and Technology, 34: 341-350.

Miyasaki, K.T, Genco, R.J., Wilson, M.E., 1986. Antimicrobial properties of hydrogen peroxide and sodium bicarbonate individually and in combination against selected oral, gram-negative, facultative bacteria. Journal of Dental Research, 65: 1142-1148.

Nisa, T., Wani, A.H., Bhat, M.Y., Pala, S.A., Mir, R.A., 2011. In vitro inhibitory effect of fungicides and botanicals on mycelial growth and spore germination of Fusarium oxysporum. Journal Biopest, 4(1): 53-56.

Olivier, C., Halseth, D.E., Mizubuti, E.S.G., Loria, R., 1998. Postharvest application of organic and inorganic salts for 
suppression of silver scurf on potato tubers. Plant Disease, 82: 213-217.

Olivier, C., MacNeil C.R., Loria R., 1999. Application of organic and inorganic salts to field-grown potato tubers can suppress silver scurf during potato storage. Plant Disease 83:814-818.

Orbovic, V., Syvertsen, J.P., Bright, D., Van Clief, D.L., Graham, J.H., 2008. Citrus seedling growth and susceptibility to root rot as affected by phosphite and phosphate. Journal Plant Nutrition, 31: 774-787.

Palmer, C.L., Horst, R.K., Langhans, R.W., 1997. Use of bicarbonates to inhibit in vitro colony growth of Botrytis cinerea. Plant Disease, 81:1432-1438.

Palou, L., Smilanick, J.L., Usall, J., Viñas, I., 2001. Control of postharvest blue and green molds of oranges by hot water, sodium carbonate, and sodium bicarbonate. Plant Disease, 85: 371-376.

Palou, L., Usall, J., Smilanick, J.L., Aguilar, M-J., Viñas, I., 2002. Evaluation of food additives and low-toxicity compounds as alternative chemicals for the control of Penicillium digitatum and $P$. italicum on citrus fruit. Pest Management Science, 58: 459-466.

Prodi, A., Sandalo, S., Tonti, S., Nipoti, P., Pisi, A., 2008. Phialophora-like fungi associated with kiwifruit elephantiasis. Journal of Plant Pathology, 90: 487-494.

Punja, Z.K., Grogan, R.G., 1982. Effects of inorganic salts, carbonate-bicarbonate anions, ammonia, and the modifying influence of $\mathrm{pH}$ on sclerotial germination of Sclerotium rolfsii. Phytopathology, 72: 635-639.

Punja, Z.K., Gaye, M.M., 1993. Influence of postharvest handling practices and dip treatments on development of black root rot on fresh market carrots. Plant Disease 77:989-995.

Reuveni, M., Agapov, V., Reuveni, R., 1996. Controlling powdery mildew caused by Sphaerotheca fuliginea in cucumber by foliar sprays of phosphate and potassium salts. Crop Prot., 15: 49-53.

Russell, A.D., 2005. Mechanisms of action, resistance, and stress adaptation. In: Michael Davidson P, Sofos JN, Branen AL. (eds) Antimicrobials in Food, 3rd edn. Boca Raton, FL, USA, CRC Press, pp 633-657.

Talibi, I., Askarne, L., Boubaker, H. Boudyach, E.H., Aoumar, A.A.B., 2011. In vitro and In vivo antifungal activities of organic and inorganic salts against citrus sour rot agent Geotrichum candidum. Plant Pathology Journal, 10: 138-145.

TÜİK, 2016. https://biruni.tuik.gov.tr/ (ErişimTarihi: 10.10.2016).

Türkkan, M., 2013. Antifungal effect of various salts againts Fusarium oxysporum f.sp. cepae the causal agent of Fusarium basal root of onion. Tarım Bilimleri Dergisi (Journal of Agricultural Sciences), 19: 178-187.

Türkkan, M., Erper, İ., 2014. Evaluation of antifungal activity of sodium salts againts onion basal rot caused by
Fusarium oxysporum f.sp. cepae. Plant Protection Science, 50(1);19-25.

Türkkan, M., 2015. Evaluation of inhibitory effect of organic and inorganic salts againts Ilyonectria liriodendri, the causal agent of root rot disease of kiwifruit. Journal Phytopathology, 163(7-8):567-577.

Türkkan, M., Erper, İ., 2015. Inhibitory influence of organic and inorganic sodium salts and synthetic fungicides againts bean root rot pathogens. Gesunde Pflanzen, 67: 83-94.

Türkkan, M., 2017. Ordu ili kivi bahçelerinde görülen fungal kök çürüklüğü hastalık etmenlerinin belirlenmesi. ORDU BAP tarafindan desteklenen TF-1306 nolu projenin sonuç raporu, Ordu, 22s.

Thomidis, T., Exadaktylou, E., 2010. Effect of boron on the development of brown rot (Monilinia laxa) on peaches. Crop Protection, 29(6): 572-576.

Thompson, D.P., 1989. Fungitoxic activity of essential oil components on food storage fungi. Mycologia, 81: 151153.

Tripathi, P., Dubey, N.K., Banerji, R., Chansouria, J.P.N., 2004. Evaluation of some essential oils as botanical fungi toxicants in management of post-harvest rotting of citrus fruits. World Journal of Microbiology and Biotechnology, 20: 317-321.

Valencia-Chamorro, S.A., Palou, L., del Rio, M.A., PerezGago, M.B., 2008. Inhibition of Penicillium digitatum and Penicillium italicum by hydroxypropyl methylcellulose- lipid edible composite films containing food additives with antifungal properties. Journal of Agricultural and Food Chemistry, 56: 11270-11278.

Vir, D., Vaidya, A., 1987. Efficacy of fungicides XLI. Relative efficacy of fungicides as post harvest chemical treatment for control of Fusarium species causing spoilage and loss of oil in stored groundnut. International Journal of Tropical Plant Disease, 5: 211216.

Yangui, T., Rhouma, A., Triki, M.A., Gargouri, K., Bouzid, J., 2008. Control of damping-off caused by Rhizoctonia solani and Fusarium solani using olive mill waste water and some of its indigenous bacterial strains. Crop Protection, 27: 189-197.

Yonat, H., 2016. Ordu ili kivi bahçelerinde görülen yabancı ot türlerinin ve yoğunluklarının belirlenmesi Yüksek Lisans Tezi, Ordu Üniversitesi, Fen Bilimleri Enstitüsü, Bitki Koruma Anabilim Dalı, Ordu.

Yuen, G.Y., Schroth, M.N., Weinhold, A.R., Hancock, J.G., 1991. Effects of soil fumigation with methyl bromide and chloropicrin on root health and yield of strawberry. Plant Disease, 75: 416-420.

Ziv, O., Zitter, T.A., 1992. Effects of bicarbonate and filmforming polymers on cucurbit foliar diseases. Plant Disease, 76: 513-517. 